\title{
Bacterial vaginosis: more questions than answers
}

Background and epidemiology:

Bacterial vaginosis is a common condition with a poorly understood etiology, natural history and public health burden. It seems to result from an imbalance of the normal vaginal flora, with an overgrowth of anaerobic bacteria and a reduction in lactobacillary flora. It can be associated with the production of a malodorous vaginal discharge and, on occasion, vaginal burning or itching. The implicated microorganisms include Gardnerella vaginalis, Ureaplasma urealyticum, Mycoplasma bominis, Mobiluncus species, Prevotella species and other anaerobes, although no single bacterial agent consistently predominates. ${ }^{1}$

Typically, bacterial vaginosis \pm is diagnosed if 3 of the following 74 criteria are present: a vaginal $\mathrm{pH}$ higher than 4.5 ; the presence of clue (vaginal epithelial) cells in the vaginal fluid; a thin, grey or white homogenous discharge;

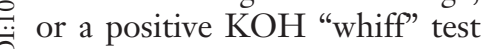
(the release of an amine [fishy]

Box 1: Recommended regimens for the treatment of bacterial vaginosis

Nonpregnant women

- Metronidazole $500 \mathrm{mg}$ orally twice a day $\times 7 \mathrm{~d}$

OR

- Metronidazole gel $0.75 \%$, one full applicator (5 g) intravaginally once a day $\times 5 \mathrm{~d}$

OR

- Clindamycin cream 2\%, one full applicator (5 g) intravaginally at bedtime $\times 7 \mathrm{~d}$

\section{Pregnant women}

- Metronidazole $250 \mathrm{mg}$ orally 3 times a day $\times 7 \mathrm{~d}$ OR

- Clindamycin $300 \mathrm{mg}$ orally twice a day $\times 7 \mathrm{~d}$

Note: Patients should be advised to avoid consuming alcohol during treatment with metronidazole and for 24 hours thereafter. Clindamycin cream and ovules are oil-based and might weaken latex condoms and diaphragms. Refer to condom product labelling for additional information.

Source: US Centers for Disease Control and Prevention. Sexually transmitted diseases treatment guidelines 2002. MMWR Morb Mortal Wkly Rep 2002;51(no. RR-6). odour upon the addition of $10 \%$ potassium hydroxide to the vaginal fluid). ${ }^{2}$

The prevalence of bacterial vaginosis is estimated to be from $25 \%$ to $36 \%$ among women attending gynecologic and STD clinics. ${ }^{2}$ However, about half of the women who meet the laboratory criteria for the infection have no symptoms, which raises questions about the need to screen and treat women for bacterial vaginosis. ${ }^{2}$

To evaluate the implications of untreated infection, the US Centers for Disease Control and Prevention (CDC) Bacterial Vaginosis Working Group reviewed the available evidence on the adverse sequelae of bacterial vaginosis. ${ }^{1}$ It found a clear association between the condition and adverse pregnancy outcomes and infectious complications of certain gynecologic procedures. It also found some evidence that the presence of bacterial vaginosis increases the risk of HIV infection. However, evidence to support either targeted or general routine screening and treatment of bacterial vaginosis is sparse. A recent Cochrane review reported that treatment did not significantly reduce the risk of preterm birth and that current evidence did not support screening all pregnant women and treating those with asymptomatic bacterial vaginosis. ${ }^{3}$ A randomized community trial that evaluated the treatment of bacterial vaginosis to prevent HIV infection found it to be ineffective in changing the prevalence and impact of bacterial vaginosis.

The CDC Bacterial Vaginosis Working Group also concluded that currently recommended treatment regimens (Box 1) are less than optimal. The effectiveness of recommended therapies at 3-4 weeks is about $80 \%$, and the recurrent rate within 1 month after therapy is as high as $20 \%$.
Clinical management: Current recommendations support testing all women who are symptomatic or who, on physical examination, have a vaginal discharge suggestive of bacterial vaginosis (www.cdc.gov/mmwr/preview /mmwrhtml/rr5106a1.htm). In general, follow-up visits after treatment and routine treatment of sex partners are not recommended. The guidelines also support testing and treating pregnant women with a history of premature delivery as well as evaluating the effectiveness of treatment 1 month after completion of treatment. Women who are undergoing surgical abortion or hysterectomy should also be tested and treated.

Prevention: Primary and secondary prevention of bacterial vaginosis is hampered by a lack of information about the condition's natural history and the ecology of the vaginal flora, less than optimal treatment regimens and the lack of welldesigned studies evaluating the effectiveness of screening and treatment in specific populations. Uncertainty about risks fuels controversial interpretations and inconsistent standards of care.

\section{Erica Weir}

Associate Medical Officer of Health Kingston, Frontenac and Lennox \& Addington Health Unit Kingston, Ont.

\section{References}

1. Koumans EH, Kendrick JS; CDC Bacterial Vaginosis Working Group. Preventing adverse sequelae of bacterial vaginosis: a public health program and research agenda. Sex Transm Dis 2001;28:292-7.

2. Sweet R. Gynecologic conditions and bacterial vaginosis: implications for the non-pregnant patient. Infect Dis Obstet Gynecol 2000;8:184-90.

3. McDonald H, Brocklehurst P, Parsons J, Vigneswaran R. Antibiotics for treating bacterial vaginosis in pregnancy. Cochrane Database Syst Rev 2003(2):CD000262. 